\title{
Self-perceived quality of life in cocaine dependents with or without dual diagnosis
}

\author{
Sira Díaz-Morán, ${ }^{1}$ Raúl Felipe Palma-Álvarez, ${ }^{2}$ Lara Grau-López, ${ }^{2,3}$ Constanza Daigre, ${ }^{3}$ Carmen Barral, ${ }^{2,3}$ \\ Elena Ros-Cucurull, 1,2,3 Miguel Casas, ${ }^{1,2}$ Carlos Roncero',2,3
}

Original article

\section{ABSTRACT}

\section{Introduction}

Although impairment in the quality of life is common among cocaine dependent patients, there are but a few researches about the interaction between addiction and quality of life.

\section{Objective}

To study different parameters of quality of life in a sample of cocaine dependent patients and to compare patients with or without dual diagnosis. Also, to promote the importance of subjectivity in the quality of life and to propose to incorporate patients' self-perception into their treatment.

\section{Method}

Three diagnostic interviews were administered (SCID-I, SCID-II and PRISM) and a quality of life questionnaire (SF-36) was applied between two different patient groups: Group I (cocaine dependent patients) and Group II (cocaine dependent patients with other mental disorder).

\section{Results}

Patients diagnosed with dual disorders (Group II) showed broader differences in perceptions of their quality of life in comparison with their clinicians. The perception of quality of life may vary depending on the presence and severity of mental disorders, and these different appreciations may explain the difficulties that clinicians face in understanding their patients' expectations and motivations.

\section{Discussion and conclusion}

A systematic evaluation of the subjective quality of life should be included in the management of cocaine dependent patients in order to more accurately understand the patients' perception of their treatment, motivations and expectations.

Key words: Substance-related disorders, cocaine dependence, quality of life, personal satisfaction, mental health, dual diagnosis.

\section{RESUMEN}

\section{Introducción}

La calidad de vida de los pacientes dependientes a la cocaína se encuentra alterada y hay poca información acerca de cómo interactúa la dependencia a sustancias y la calidad de vida.

\section{Objetivo}

Estudiar los diferentes parámetros de calidad de vida en pacientes dependientes a la cocaína con o sin diagnóstico de patología dual. Asimismo, señalar la importancia de la subjetividad en la calidad de vida y proponer la incorporación de la autopercepción de los pacientes en su tratamiento.

\section{Método}

Se realizaron tres entrevistas diagnósticas (SCID-I, SCID-II y PRISM) y un cuestionario de calidad de vida (SF-36) entre dos grupos diferentes de pacientes: Grupo I (pacientes con dependencia a la cocaína solamente) y Grupo II (pacientes dependiente a la cocaína con otro trastorno mental).

\section{Resultados}

Los pacientes diagnosticados con patología dual (Grupo II) mostraban amplias diferencias en la percepción de la calidad de vida comparada con la percepción de sus terapeutas. La percepción de la calidad de vida podría variar dependiendo de la presencia y gravedad de los trastornos mentales asociados. Además, estas diferentes apreciaciones podrían explicar las dificultades que tiene el clínico para entender las expectativas y motivaciones del paciente de cara a su tratamiento.

\section{Discusión y conclusión}

En pacientes dependientes a la cocaína debería realizarse de forma sistemática una evaluación de la calidad de vida subjetiva con el fin de conocer con mayor precisión la percepción que tienen los pacientes de su tratamiento, así como sus motivaciones y expectativas.

Palabras clave: Trastornos por uso de sustancias, dependencia a cocaína, calidad de vida, satisfacción personal, salud mental, patología dual.

\section{Department of Psychiatry and Forensic Medicine. Neuroscience Institute. Autonomous University of Barcelona. Barcelona (Spain). \\ 2 Psychiatry Service. Vall d'Hebron University Hospital. CIBERSAM. Barcelona (Spain). \\ Addiction and Dual Diagnosis Unit. Vall d'Hebron University Hospital. Barcelona -Public Health Agency (ASPB) Barcelona (Spain).}

Correspondence: Carlos Roncero, MD PhD. Department of Psychiatry, Vall d'Hebron University Hospital. Passeig Vall d'Hebron, 119-129, 08035 Barcelona, Spain. Tel: +3493 489-4295; fax: +3493 489-4587. E-mail: croncero@vhebron.net

Received fist version: May 5, 2015. Second version: October 1st, 2015. Accepted: October 26, 2015 


\section{INTRODUCTION}

Evaluation of the psychopathological characteristics in cocaine dependent patients has gained interest in recent years. ${ }^{1,2}$ Patients with substance use disorders (SUD) and other comorbid mental disorders are called dual diagnosis or dual disorder patients (DD). These patients have little awareness of their disease. ${ }^{3}$ In psychiatry, it is recommended to complete subjective evaluations with the clinician appreciation's. ${ }^{4}$ One of the reasons for which the health professionals consider patients experiences is because often patients' perceptions and professionals' evaluations are different, and this may occur more frequently in DD patients. ${ }^{5}$

There are a lot of definitions of quality of life (QL) related to health in drug-dependent patients ${ }^{6}$ and there is no operative QoL definition. ${ }^{6,7}$ QoL is conceptualized as a multidimensional construct; 8 currently, the self-perceived dimension is being intensely studied. ${ }^{8}$ Other studies have suggested that personal characteristics, self-concept and clinical characteristics are mediating factors, and these may influence the subjective perception of QoL. ${ }^{9}$

The purpose of QoL evaluation should be more than the presence and severity of the symptoms, ${ }^{10}$ but it should also be important to examine how drug users can appreciate and experience this effect in their lives. It has been found that satisfaction is the most appropriate concept to encompass various aspects of self-perceived QoL. ${ }^{11}$ Although QoL is an inherently subjective construct, traditionally, a distinction has been made between clinician and patient perceptions. Nevertheless, there are no studies evaluating clinician's and patient's concordance of perceptions.

The aims of this study are to compare the QoL perception between cocaine dependent patients and clinicians and to study the differences between DD and non-DD patients.

\section{METHOD}

\section{Study site and subjects}

We used a cross-sectional design. Two groups of patients were included in the sample: 1 . Cocaine dependent patients without another concomitant mental disorder, and 2. Cocaine dependent patients with another mental disorder.
The criteria for sample selection were as follows: 1. only Spanish patients were included in order to avoid cultural interferences in the results; 2 . clinical interviews confirmed that patients should have sufficient cognitive abilities, and good understanding of the information sheet and informed consent. Patients did not receive financial compensation for their participation in the study. A consecutive sampling method was applied. Accordingly, all inpatients who were attended in ambulatory care or admitted to the Detoxification Hospital Unit, and met inclusion/exclusion criteria, were included in the study.

Inclusion criteria were cocaine dependence with or without nicotine dependence, and in group two have also been diagnosed with another mental disorder as comorbidity. Exclusion criteria were the following: 1. patients who presented another drug dependence (except cocaine and nicotine dependence), 2. patients who presented mental disorders due to medical illness or drugs.

\section{Study design and outcome measures}

The period of data collection was between January and December of 2009. This study was approved by the Clinical Research Ethics Committee of the University Hospital Vall d'Hebron. The Spanish version of the short-form of the SF-36 was administered. ${ }^{12}$ Furthermore, three diagnostic interviews were conducted: SCID-I, SCID-II and PRISM. Different patients' and clinicians' QoL scale scores were considered dependent variables, and psychiatric diagnoses was considered independent variables. Two trained clinical evaluators conducted the diagnostic interviews in order to verify the diagnostic inter-rater reliability (for 10 out of 60 cases).

\section{Statistical analysis}

Firstly, a frequency and exploratory descriptive analysis, on clinicians' and patients' QoL perspectives was applied. Student's t-tests for independent groups were also applied for comparisons between DD and non-DD group values, and between clinicians' and patients' responses. In addition, a correlation matrix was applied to study the associations between clinicians' and patients' responses on SF-36 dimensions.

Table 1. Sociodemographic sample description

\begin{tabular}{lccrrr}
\hline & $\begin{array}{c}\text { Dual disorder patients } \\
n=28\end{array}$ & $\begin{array}{c}\text { Non-dual disorder patients } \\
n=32\end{array}$ & OR & Confidence interval & Entire sample \\
\hline Age & $33.8(21-61)$ & $33(23-59)$ & & & $33.4(21-61)$ \\
Gender (Man \%) & $24(86 \%)$ & $26(81 \%)$ & 1.39 & $0.35-5.51$ & $50(83.3 \%)$ \\
Cohabitation (alone) & $4(13.3 \%)$ & $4(12.5 \%)$ & 1.16 & $0.26-5.17$ & $9(13.3 \%)$ \\
Children (\%) & $8(29 \%)$ & $8(25 \%)$ & 0.83 & $0.27-2.62$ & $16(26.7 \%)$ \\
Employed (\%) & $9(34 \%)$ & $14(44 \%)$ & 0.61 & $0.12-1.75$ & $23(38.3 \%)$ \\
\hline
\end{tabular}

OR $=$ Odds ratio. 
Table 2. Psychiatric comorbidity description in the sample $(n=60)$

\begin{tabular}{llrr}
\hline & & $n$ & \multicolumn{1}{c}{$\%$} \\
\hline Non-dual diagnosis & Cocaine dependence & 32 & 53.3 \\
Dual diagnosis & 1 & 6.0 \\
& Dysthymic disorder & 7 & 41.0 \\
& Induced anxiety disorder & 1 & 6.0 \\
& Schizophrenia & 7 & 41.0 \\
& Induced psychotic disorder & 1 & 6.0 \\
& Agoraphobia & 11 & 18.3 \\
& Any personality disorder & 28 & 46.6 \\
\hline
\end{tabular}

\section{RESULTS}

High correlations were obtained for the inter-rater reliability $(0.98)$ in the diagnostic patients. Table 1 provides sociodemographic information on the sample. The DD and non-DD patient samples $(n=60)$ did not differ significantly with respect to age, cohabitation type and employment status (chisquare test, $p>0.05$ ). From the total, $83.3 \%$ were men, with a mean age of 33.4 \pm 8.1 years (range 21-61). Overall patients had a primary education level (58.4\%) and parental cohabitation accounted for $48.3 \%$ of the sample.

Cocaine was the primary substance of abuse, but $80 \%$ of the patients also showed nicotine dependence, $33.3 \%$, alcohol abuse, and 10\%, cannabis abuse (table 2). Regarding mental disorders comorbidity, table 2 shows also a dual pathology proportion (28/60) for the entire sample.

The correlation matrix (table 3) mainly shows: 1 . low to moderate direct correlations ( $r=0.26$ to 0.48 ) between clinician and patient responses of the SF-36 dimensions (especially between vitality, emotional well-being and physical role); 2. moderate to high correlations among those from (and within) the clinician responses ( $r=0.49$ to 0,70 , especially between emotional well-being, general health, vitality and social function); and also within the patient responses $(r=0.43$ to $r=0.71$ ) between emotional well-being and vitality.

Table 4 shows the comparison between patients' and clinicians' responses in the different SF-36 scale dimensions. As it can be observed, there are basically two dimensions with statistical significant differences between dual and non-dual pathology patients. This differences account for patients' perspective and also for clinicians' perspective (physical functioning for patient responses, $\mathrm{F}[58]=6.4, p=$ 0.01; physical functioning and vitality for clinician responses, $\mathrm{F}[58]=4.5, p<0.05$, indicated by an asterisk in table 3 ). To general differences with dual pathology patients (Group II) and clinician appreciation, it showed significant differences in most dimensions of the SF-36 scale (all Fs(58) $\geq 5.5$, $p<0.05)$, in contrast to what occurred in the comparison between cocaine dependence patients (Group I) and clinician appreciation, in which there are not many differences as in the other groups.

No sociodemographic covariate effects were found to be statistically significant. 
Díaz-Morán et al.

Table 4. Different perspectives in quality of life: a comparison between patients and clinicians in the SF-36 dimensions

\begin{tabular}{|c|c|c|c|c|}
\hline \multirow{3}{*}{ SF-36 dimensions } & \multicolumn{2}{|c|}{ Patient responses } & \multicolumn{2}{|c|}{ Clinician responses } \\
\hline & Dual disorder patients & Non-dual disorder patients & Dual disorder patients & Non-dual disorder patients \\
\hline & Mean \pm SD & Mean \pm SD & Mean \pm SD & Mean \pm SD \\
\hline Physical functioning & $78.0 \pm 29.8$ & $92.0 \pm 8.9 *$ & $75.5 \pm 27.1$ & $85.9 \pm 14.4^{*}(b)$ \\
\hline Physical role & $75.0 \pm 37.9$ & $68.4 \pm 42.4$ & $37.5 \pm 43.8(a)$ & $47.2 \pm 44.9$ \\
\hline Pain & $63.4 \pm 30.9$ & $74.2 \pm 30.9$ & $64.1 \pm 29.7$ & $70.0 \pm 27.3$ \\
\hline General health & $63.3 \pm 19.5$ & $64.8 \pm 17.9$ & $43.6 \pm 14.7(a)$ & $52.9 \pm 14.9(b)$ \\
\hline Vitality & $49.6 \pm 25.5$ & $59.5 \pm 18.3$ & $46.9 \pm 17.9$ & $52.6 \pm 13.2^{*}$ \\
\hline Social function & $58.9 \pm 29.8$ & $59.4 \pm 28.0$ & $42.4 \pm 22.4(a)$ & $49.6 \pm 23.1$ \\
\hline Emotional role & $47.6 \pm 44.8$ & $51.3 \pm 44.9$ & $9.5 \pm 23.8(a)$ & $24.8 \pm 36.9(b)$ \\
\hline Emotional well-being & $49.7 \pm 23.4$ & $53.3 \pm 20.6$ & $35.7 \pm 16.7(a)$ & $42.1 \pm 15.3(b)$ \\
\hline
\end{tabular}

Dual disorder patients, $n=28$ and non-dual pathology patients, $n=32$.

(a) $p<0.05$ clinician responses vs. dual disorder patients responses (one-way ANOVA).

(b) $p<0.05$ clinician responses vs. non-dual disorder patients (one-way ANOVA).

${ }^{\star} p<0.05$ vs. dual disorder patients in clinician and patient responses (one-way ANOVA).

\section{DISCUSSION AND CONCLUSION}

The present research shows the QoL appreciations from a clinical evaluation from cocaine dependent patients with or without other mental disorder. The singularity of this report is the description of clinician and patient discrepancies about their QoL assessment, according to the subjective assessment of quality of life. ${ }^{6}$

All cocaine dependent patients expressed a worse QoL than normal average population. ${ }^{10,13}$ Although there are few data in the literature, previous findings stated that the greater the severity of cocaine use, the worse QoL. ${ }^{7}$

In drug addiction, two factors have been described for treatment adherence: psychopathology and the severity of addiction. ${ }^{14}$ According to these authors, the low level of treatment adherence is related to the lack of disease awareness and the balance to perform between the positive effect of going to treatment and the immediate reinforcement of drug consumption. ${ }^{14}$ Other important factors influencing the QoL perception are cognitive schemes, motivation to continue the treatment, social environment and psychiatric comorbidity. ${ }^{10}$

Based on previous studies, we might consider the evaluation of QoL as an indicator of the evolution of patient satisfaction in different areas of life, ${ }^{8}$ as well as an indicator in the progression of treatment. ${ }^{15}$ Otherwise, QoL could be considered as an indicator of severity in the assessment of mental disorders and specifically in the field of drug addiction, since previous studies indicate that DD patients have worse QoL in comparison with patients without DD. ${ }^{16}$ These findings are consistent with results of other studies that show the clinical characterization of DD patients: poor prognostic defined by more number of relapses, short abstinence time and greater tendency to chronicity. ${ }^{17}$

Several longitudinal studies have described that changes in QoL showed inverse correlation with changes in the mental disorders severity. ${ }^{9,18}$ It is important to note that QoL is a subjective construct ${ }^{19}$ and for this reason it would be consistent to think that this perception is conditioned by the presence of mental disorders, and therefore it has a paradoxical interpretation. For instance, QoL appreciation of patients with psychosis combined with substance use disorders has a tendency to be better than QoL levels perceived by their clinicians, opposite to what happens in patients with mood disorders. ${ }^{20}$ This discrepancy could be explained partially by the Distress/Protection Model for psychotic patients. ${ }^{21}$ This model describes QoL as the result of the interaction between stress and protection factors. If the stress factors are higher than protection factors, then the perception of QoL decreases. It has been shown some cognitive deficits, and form and content thought alterations in psychotic patients. These deficits questioned the validity of patients' scores presented. ${ }^{8}$

According to patients' responses, it has been observed a clear trend towards explaining greater satisfaction of their QoL in all SF-36 dimensions in the DD patient sample compared to the non-DD. Nevertheless, due to the diagnoses heterogeneity, the QoL assessing threshold used between DD and non-DD patients was significantly different in two dimensions only (physical functioning and vitality). In contrast to happened in clinical responses, from which DD patients had lower QoL in comparison with non-DD patients.

However, some studies claim that the insight improvements are linked with decreased differences between patients' and clinicians' perceptions. ${ }^{22}$ The presence of another mental disorder in drug-dependent patients could influence the subjective assessment of their context, and in consequence, it would be responsible for the discrepancy between clinician and patient.

Some factors that play a significant role in QoL has been described: self-concept, self-efficacy, type of coping style, 
personality traits, emotional expression and social support. ${ }^{21}$ Some differences were found in sociodemographic characteristics, but these differences were not statistically significant. Hence, we cannot evaluate the degree of influence of social status on the satisfaction QoL assessment. It is possible that DD patients' values could be different for similar social features, in comparison with non-DD patients. ${ }^{23}$ Due to these differences, it will be important to evaluate in future studies the influence of DD in the QoL assessment, and especially in social environment, labour and mental health dimensions.

In this study we also found differences between clinicians' and patients' responses, especially in comparison with DD patients' responses. It is important to analyze what implications might have these discrepancies on the treatment evolution, ${ }^{22,24}$ as well as other studies have shown that SF-36 administration can discriminate patients in different stages of treatment and assess their progression. ${ }^{25}$ According to previous studies, ${ }^{24}$ only the wellness perception is a predictor of treatment success and the self-efficacy and QoL perception are related to underlying personality traits, and thus the evaluation of these traits is a priority to define the goals of treatment and its effectiveness.

As limitations of the study, it should be pointed out that a heterogeneous group of DD patients were included in the sample and psychiatric disorders were not analysed separately due to the small sample size. Moreover, subjective evaluations of QoL have been developed to assess patients with chronic diseases. Consequently, in mental illness and SUD, the same model could not be extrapolated because the disability caused by these disorders could be qualitatively different. ${ }^{26}$

In accordance with these results, it may be concluded that: 1 . the perception of QoL may vary depending on the presence and kind of mental disorders; and 2. it is recommended to include a systematic evaluation of subjective QoL to understand more accurately the patients' perception of their treatment, motivations and expectations.

\section{Funding}

Supported by grants from the General Deputy Division for Drug Addictions (Health Departament, Generalitat de Catalunya) for cocaine dependence research. Also, a Grant from the Instituto Carlos III: FIS PI13/1911 "Alucinaciones cenestésicas: factor pronóstico en dependientes de cocaína" and, a Grant from the Delegación del Gobierno para el Plan Nacional sobre Drogas 2013I044: "Complicaciones clínicas y accidentabilidad asociadas a la presencia de síntomas psicóticos en consumidores de cocaína". The PND and FIS had no further role in the study design; in the collection, analysis and interpretation of data; in the writing of the report; and in the decision to submit the paper for publication.

\section{Conflict of interests}

No authors of this paper has a conflict of interest, including specific financial interest, relationships, and/or affiliations relevant to the subject matter included in this manuscript.

\section{Acknowledgements}

The authors would like to thank Dr. Ángel Egido (Outpatient Clinic Valld' Hebron, Valld' Hebron University Hospital), Dr. Sergi Valero (Department of Psychiatry, Valld' Hebron University Hospital) and Dr. Albert Fernández-Teruel (Medical Psychology Unit, Department of Psychiatry and Legal Medicine, UAB) for their collaboration in this article.

\section{REFERENCES}

1. Del Bosque J, Fuentes Mairena A, Diaz DB, Espínola M et al. La cocaína: consumo y consecuencias. Salud Ment 2014;37:381-389.

2. Roncero C, Daigre C, Grau-López L, Barral C et al. An international perspective and review of cocaine-induced psychosis: a call to action. Subst Abus 2014;35(3):321-327.

3. Roncero C, Gómez-Baeza S, Vázquez JM, Terán A et al. Perception of Spanish professionals on therapeutic adherence of dual diagnosis patients. Actas Esp Psiquiatr 2013;41(6):319-329.

4. Bobes J, Gutiérrez M, Gibert J, González MP et al. Quality of life and disability in chronic schizophrenics treated with with risperidone and previously treated with depot neuroleptics. Actas Esp Psiquiatr 1999;27(4):229-234.

5. Torrens M, San L, Martinez A, Castillo C et al. Use of the Nottingham Health Profile for measuring health status of patients in methadone maintenance treatment. Addiction 1997;92(6):707-716.

6. Roncero C, Díaz-Morán S, Comín M, Miquel L et al. Quality of life concept evolution: the subjective dimension as a relevant factor on drug addiction. Vertex 2011;22(99):343-349.

7. Lozano OM, Domingo-Salvany A, Martinez-Alonso M, Brugal MT et al. Health-related quality of life in young cocaine users and associated factors. Qual Life Res 2008;17(7):977-985.

8. Bengtsson-Tops A, Hansson L, Sandlund M, Bjarnason $\mathrm{O}$ et al. Subjective versus interviewer assessment of global quality of life among persons with schizophrenia living in the community: a Nordic multicentre study. Qual Life Res 2005;14(1):221-229.

9. Holloway F, Carson J. Subjective quality of life, psychopathology, satisfaction with care and insight: an exploratory study. Int J Soc Psychiatry 1999;45(4):259-267.

10. Foster JH, Powell JE, Marshall EJ, Peters TJ. Quality of life in alcohol-dependent subjects-a review. Qual Life Res 1999;8(3):255-261.

11. Pedrero E, Olivar A, Chicharro J. CAD-4 Questionnaire, a biopsychosocial measure of selfperceived quality of life in drug-dependent patients. Trastornos Adictivos 2008;10(1):17-31.

12. Iraurgi I, Jiménez-Lerna JM, Landabasco M. Analysis of the psychometric characteristics of the SF-36 index as an outcome indicator of drugs addiction. Psiquiatría.com 2005;9(2). [serial on-line, cited 1/08/2010]. Avaliable in www.psiquiatria.com

13. Morales-Manrique CC, Palepu A, Castellano-Gomez M, Aleixandre-Benavent $\mathbf{R}$ et al. Cocaine Group Comunidad Valenciana. Quality of life, needs, and interest among cocaine users: differences by cocaine use intensity and lifetime severity of addiction to cocaine. Subst Use Misuse 2011;46(4):390-397.

14. Secades-Villa R, García-Rodríguez O, Fernández-Hermida JR, Carballo JL. Psychological bases of the treatment of drug-dependence. Papeles Picólogo 2007;28(1):29-40.

15. Morales-Manrique CC, Tomás-Dols S, Zarza-González M, Vidal-Infer A et al. Comparative study of the perceived quality of life of patients in treatment for cocaine and heroin dependence in Spain: differences by gender and time in treatment. Subst Use Misuse 2014;49(10):1353-1358.

16. Laudet AB, Becker JB, White WL. Don't wanna go through that madness no more: quality of life satisfaction as predictor of sustained remission from illicit drug misuse. Subst Use Misuse 2009;44(2):227-252. 
17. Schmitz JM, Stotts AL, Averill PM, Rothfleisch JM et al. Cocaine dependence with and without comorbid depression: a comparison of patient characteristics. Drug Alcohol Depend 2000;60(2):189-198.

18. Priebe S, Roeder-Wanner UU, Kaiser W. Quality of life in first-admitted schizophrenia patients: a follow-up study. Psychol Med 2000;30(1):225-230.

19. Lehman AF, Ward NC, Linn LS. Chronic mental patients: the quality of life issue. Am J Psychiatry 1982;139(10):1271-1276.

20. Rudolf $\mathrm{H}$, Priebe S. Subjective quality of life in female in-patients with depression: a longitudinal study. Int J Soc Psychiatry 1999;45(4):238246.

21. Richter D, Eikelmann B, Berger K. Use of the SF-36 in the evaluation of a drug detoxification program. Qual Life Res 2004;13(5):907-914.

22. Kievit W, Hendrikx J, Stalmeier PF, van de Laar MA et al. The relationship between change in subjective outcome and change in disease: a potential paradox. Qual Life Res 2010;19(7):985-994.
23. Astals M, Domingo-Salvany A, Buenaventura CC, Tato J et al. Impact of substance dependence and dual diagnosis on the quality of life of heroin users seeking treatment. Subst Use Misuse 2008;43(5):612-632.

24. Chicharo J. Indicator variables and evolution in addicted patients. Its relation to personality traits. Psicologia.com 2005; 9(2). [serial on-line, cited 10/07/2009]. Avaliable in www.psiquiatria.com

25. Morales-Manrique CC, Palepu A, Castellano-Gomez M, Aleixandre-Benavent $\mathrm{R}$ et al. Cocaine Group Comunidad Valenciana. Quality of life, needs, and interest among cocaine users: differences by cocaine use intensity and lifetime severity of addiction to cocaine. Subst Use Misuse 2011;46(4):390-397.

26. Berlim MT, Fleck MP. "Quality of life": a brand new concept for research and practice in psychiatry. Rev Bras Psiquiatr 2003;25(4):249252. 